\title{
A TRADUÇÃO COMO MEDIAÇÃO CULTURAL: AS TRADUÇÕES DA OBRA DE JUNOT DIAZ
}

\author{
Livia Souza ${ }^{1 \times}$ \\ ${ }^{1}$ Universidade Federal da Integração Latino Americana, Foz do Iguaçu, Paraná, Brasil
}

\section{Resumo}

O presente artigo $^{1}$ tem como objeto as traduções dos livros do escritor dominicano-estadunidense Junot Díaz para o espanhol, com especial ênfase no trabalho da tradutora de origem cubana Achy Obejas. Autor de uma obra curta porém marcante, Díaz elabora suas narrativas a partir de um inglês que com frequência incorpora elementos do espanhol. Sua poética escritural inclui desde léxico do espanhol caribenho até estruturas sintáticas e ritmo próprios de seu idioma natal, o que resulta em um texto marcadamente híbrido. A tradução desse texto para um idioma tão intensamente presente no original se torna, portanto, um desafio. Para compreender como se processa a construção dessa tradução, foram analisadas as estratégias empregadas para tentar dar conta do caráter translinguístico dessas narrativas. Para atingir tal objetivo, forma utilizados como referencial teórico conceitos como o de tradução minorizante, de Lawrence Venuti; translinguismo; e as considerações de D'Amore sobre traduções de textos originalmente escritos em espanglish. A análise torna evidente que o trabalho de Achy Obejas conseguiu em grande medida dar aos textos em espanhol o mesmo caráter híbrido do original.

Palavras-chave: Literatura Dominicano-Americana; Literatura Diaspórica; Literatura Minorizante; Translinguismo

\section{TRANSLATION AS CULTURAL MEDIATION: THE TRANSLATION OF JUNOT DÍAZ BOOKS}

\section{Abstract}

This article has as its object the translations of the Dominican American writer Junot Díaz to Spanish, with special emphasis on the work of the Cuban-born translator Achy Obejas. Author of a short but remarkable work, Díaz elaborates his narratives in a variety of English that often incorporates elements of Spanish. His writing poetics includes the lexicon of Caribbean Spanish and syntactic structures and proper rhythm of his native language, which results in a strongly hybrid text. The translation of this text into a language that is so intensely present in the original is a challenge. To understand how the construction of this translation is processed, this article tries to analize the strategies used to try to keep up

\footnotetext{
* Possui mestrado (2014) e doutorado (2018) em Letras Neolatinas pela Universidade Federal do Rio de Janeiro. Atualmente é professora do ensino superior na Universidade Federal da Integração Latino Americana (Unila). Tem experiência na área de Letras, com ênfase em Literaturas Estrangeiras Modernas. Seu e-mail é: livia.souza@ unila.edu.br. ORCID: 0000-0003-4406-5415.
} 
with the translinguistic character of these narratives. In order to reach this objective, some theoretical references are used, concepts such as the foreignizing translation, by Lawrence Venuti; translingualism; and D'Amore's considerations on translations of texts originally written in Spanglish. The analysis makes it clear that the work of Achy Obejas was largely able to give the texts in Spanish the same hybrid character present in the original ones.

Keywords: Dominican-American Literature; Diasporic Literature; Foreignizing Literature; Translingualism 


\section{Introdução}

Vencedor do Pulitzer em 2012, Junot Díaz é um dos nomes mais representativos do chamado latino writing na atualidade. Seus três livros, o volume de contos Drown (1996); o romance The brief wondrous life of Oscar Wao (2007) e o híbrido This is how you lose her (2012) são poderosos exemplos da pungência da escrita elaborada por autores que podem simultaneamente ser identificados com o sistema literário norte-americano e o de seus países natais.

Cabe inicialmente justificar o trabalho com as traduções a obra de Junot Díaz para o espanhol. Opto por refletir sobre o processo de tradução das obras de Díaz porque me parece que as versões em espanhol de seus livros são fundamentais para completar uma visão de sua obra, sobretudo em relação ao âmbito da circulação e da recepção de sua escrita. Díaz é, de fato, hoje, um escritor identificado (pela crítica, pela academia e pelos mais diversos meios de circulação da literatura) com a literatura hispano-americana e é, justamente, a tradução o veículo que insere essa obra no campo intelectual hispano-americano.

Inicialmente, pode-se observar que Díaz, como define Salman Rushdie (1991) referindo-se a si próprio, é um homem traduzido. Ao abandonar seu idioma materno e fazer da língua de seu país receptor seu veículo literário, ele já empreende em alguma medida um projeto tradutório que implica uma desestabilização não só do inglês padrão como também do espanhol padrão. Sobre essa questão afirmam Bassnet e Triverdi: "By defamiliarizating the language, post-colonial writers can bring face to face with the reality of difference, and call into question the supremacy of the standard language" $\left(1999\right.$, p. 14). ${ }^{2}$

Assim, sua obra transnacional nasce já marcada pela transculturalidade, pelo translinguismo, pela multiplicidade enunciativa. As narrativas originais do autor são compostas por complexos e constantes processos de autotradução e de mediação cultural. Refletir sobre suas versões em espanhol evidencia elementos da composição literária em inglês que de outro modo seriam significativamente menos perceptíveis.

Ao mesmo tempo, as narrativas de Díaz já foram elaboradas com a expectativa de uma tradução para a língua materna do autor, como ele próprio afirma em um ensaio em que reflete sobre a tradução de Drown:

one of the things about writing in English is that there are certain members of my audience whom I clearly wanted to be able to read these texts but who didn't read in English, so I always figured that they'd end up being translated informally by one of my family members. That's about as far as I originally thought about translation $(2002$, p. 43$) .^{3}$

Portanto, as versões em espanhol podem ser consideradas, mais do que uma demanda do mercado editorial, um processo necessário para que o livro possa ser consumido por um público esperado pelo autor, mas que não tem acesso ao texto original. Nesse contexto, é preciso assumir as versões traduzidas da obra de Díaz, não como um produto menor ou sucedâneo, mas sim como uma espécie de 
re-criacão ou continuação da obra original, num processo que complementa os textos e os recoloca no campo literário.

Assim, para caracterizar a obra de Díaz como parte de um sistema literário transnacional é fundamental levar em conta suas traduções, uma vez que elas são um processo necessário para que a obra circule amplamente dentro desse sistema. Pensar o papel da literatura traduzida na atualidade é, portanto, um movimento absolutamente necessário para a compreensão dos processos de formação de cânone e para o estudo de obras que ultrapassam as fronteiras geopolíticas dos países em que são publicadas.

Para dar conta desse processo de circulação de forma efetiva, no entanto, a tradução desse tipo de livro não pode apresentar uma versão neutra, facilitadora ou domesticada do texto, como muitas vezes ocorre com narrativas com esse perfil. É fundamental pensar a tradução como um processo transcultural, refletir sobre o papel do tradutor nesse processo e repensar inclusive a própria noção de autoria nesses contextos. Além disso, é também imprescindível conceber a própria linguagem literária a partir de sua dimensão política.

Com o objetivo de tentar aproximar as obras de Díaz dessa perspectiva, cabe uma breve aproximação à concepção de tradução como projeto transcultural, levando em consideração especialmente as relações entre tradução e literatura pós-colonial e o conceito de tradução minorizante.

\section{A tradução como projeto transcultural}

$\mathrm{O}$ ato de traduzir é o símbolo máximo do encontro entre diferentes culturas e um elemento central para o estabelecimento das relações de poder no mundo colonial. Identificado muitas vezes como um ato de traição, sentido recuperado frequentemente com a célebre metáfora da Malinche, a tradução funcionou por muito tempo como um recurso que possibilitava e reforçava estruturas de dominação.

Contemporaneamente, no entanto, esse mesmo recurso é visto como uma ferramenta poderosa para a subversão das lógicas de dominação. Bassnett $\mathrm{e}$ Triverdi na introdução ao livro Post Colonial Translation (1999) estabelecem um interessante paralelo entre a ideia de canibalismo, cara ao movimento modernista brasileiro, e a concepção pós-colonial de tradução, agora entendida como um ato que metaforicamente devora a cultura dominante para a partir disso processá-la junto aos elementos locais e assim dar à luz produtos culturais tão híbridos quanto ricos.

Afirma D’Amore (2010), em um artigo sobre a tradução de textos literários originalmente escritos em Spanglish, que "la traducción ha jugado un papel significativo en la creación de estereotipos del Otro, como productos derivados de la domesticación y de la imposición cultural (p. 34)". ${ }^{4}$ Partindo dessa colocação, cabem algumas reflexões: que estratégias devem ser usadas quando se lida com um texto literário que já em sua origem foi hibridamente concebido? Como fazer dessa tradução um produto que, sem pretender espelhar o texto 
original, tarefa impossível, mantém seu caráter híbrido? Como, ainda, fazer da tradução um veículo não da domesticação do texto original, mas sim um disseminador do texto?

Tais questões parecem repetir em alguma medida algumas perguntas feitas por Derrida (2006, p.27) em "Des tours de Babel". Como traduzir um texto escrito em várias línguas ao mesmo tempo? Como "interpretar" o efeito da pluralidade? E se se traduz em várias línguas ao mesmo tempo, chamar-se-á isto de traduzir? Embora não esteja refletindo sobre a problemática de textos escritos em contextos diaspóricos da contemporaneidade, as perguntas de Derrida apontam para a complexidade da tarefa da tradução multilinguística.

Sem dúvida, essas não são questões que possibilitam respostas simples. No entanto, um caminho possível para iniciar o debate nesse sentido é compreender a tradução como um exercício transcultural. Sobre essa questão disserta Cheadle:

translation and transculturation, though analytically distinguishable terms, are nevertheless processes that in practice overlap. Just as the act of translation willy-nilly adds layers of meaning, so does the process of transculturation: A does not merely pass over and disappear into B, rather the two interact in complex and unpredictable ways to produce something new, say A1 and C, to cite the variables beautifully conjugated by Alejandro Saravia in a passage from his novel quoted by José Antonio Giménez Micó. (CHEADLE \& PELETIER, 2007, p. ix) ${ }^{5}$

Em outra passagem, Cheadle deixa claro o que entende por transculturação: "the turbulent and unpredictable process resulting from the interaction among cultures in contact and which potentiates, in spite of unequal power relations, the emergence of new cultural forms" (2007, p. xi). ${ }^{6}$

Assim, o tradutor que encara seu ofício a partir de uma perspectiva transcultural deve levar em conta, como afirma D’Amore (2010), para além das competências linguísticas que a atividade exige, o caráter diverso que a literatura assume na atualidade. De fato, a própria escrita em condições de póscolonialidade incorpora procedimentos característicos da tradução, como afirma Tymoczko (BASSNET \& TRIVEDI, 1999):

Authors also frequently provide introductions and postscripts, write critical essays commenting on their own texts, or facilitate authorized commentaries on their work. Indeed, we better understand why postcolonial authors embrace such textual types and such literary strategies by considering the functions of similar elements for translators. $(1999, \text { p. } 22)^{7}$

Díaz pode claramente ser associado às características descritas por Tymoczko. Sua obra, em especial o romance The brief wondrous life of Oscar Wao/ La maravillosa vida breve de Oscar Wao, se vale do uso de notas ficcionais, de um prólogo que mescla a história dos personagens a explicações sobre a história da República Dominicana e de frequentes alusões a autores de ficção, intelectuais e artistas das mais diversas procedências. Trata-se, inegavelmente, de um texto que 
já traz em si a marca tradutória, fazendo dessa particularidade um de seus mais ricos procedimentos estéticos.

Assim, pode-se observar que no caso específico da tradução de textos que em sua origem já são marcados por uma pluralidade linguística explícita, como é o caso de autores diaspóricos que se utilizam do code-switching característico de suas comunidades em sua produção literária, a tarefa da tradução se torna ainda mais complexa.

D’Amore (2010) propõe, nesse contexto, a adoção do que ela denomina tradução "foraneizante", ${ }^{8}$ a partir das reflexões de Venuti (2008):

Las traducciones fluidas requieren de la inversión de un menor esfuerzo debido a su lealtad primaria hacia la lengua y cultura destino, y no al texto original (TO) y su lengua y cultura. En contraste, la dificultad relativa de una traducción foraneizante sirve como un recordatorio de la alteridad del TO, a través de intervenciones que resaltan el hecho de que el texto traducido (TT) es efectivamente un texto traducido, de un texto producido en Otra lengua, en Otras circunstancias, en Otro contexto. $(2010 \text {, p. } 34)^{9}$

O tradutor que parte desse paradigma, portanto, faz da sua prática uma forma de resistência, que teria como objetivo, para D’Amore: "contrarrestar estos actos de etnocentrismo, una práctica que no contribuye a la creación de estereotipos ni a la supresión cultural, sino que tiene como meta respetar la alteridad del TO."10 Destarte, o respeito, não só pelo texto original, mas pela cultura em que ele se insere, é um elemento central para qualquer tradução que se pretenda minorizante.

Para desenvolver sua ideia de tradução minorizante, central para o presente trabalho, Venuti parte da ideia de que a língua não pode ser vista apenas como um instrumento de comunicação que obedece a um determinado conjunto de regras. Para esse autor, é necessário conceber a linguagem em uma perspectiva inspirada pelos estudos de Deleuze e Guattari "as a colective force, an assamblage of forms that constitute a semiotic regime"11 (1998, p. 9). Venuti escolhe, portanto, enxergar a linguagem a partir das relações de poder que ela movimenta, e aplica essa concepção ao universo da tradução, seu principal campo de estudo.

Venuti aponta o objetivo da tradução minorizante como: "never to erect a new standard or to establish a new canon, but rather to promote cultural innovation as well as the understanding of cultural difference by proliferating the variables within English"12 (1998, p. 11). Embora pensando traduções que têm o inglês como idioma final e não língua de partida, como é o caso dos textos trabalhados no presente artigo, as críticas ao que Venuti chama de abordagens linguísticas da tradução (linguistic-oriented approaches), em voga principalmente a partir dos anos 60, são válidas também para traduções com diferentes perfis. Para esse autor, é fundamental questionar essa forma de encarar a tradução, já que ela tende a gerar textos conservadores, que reduzem o papel do exercício tradutório enquanto motivador de mudanças sociais e inovação cultural (1998, p. 21).

Como deve ser então a tradução minorizante? No capítulo denominado heterogeneidade de seu livro "The scandals of the Translation", Venuti usa como 
exemplo uma tradução feita por ele próprio para os contos do escritor Italiano I.U. Tarchetti. Em sua versão desse texto, originalmente escrito no século XIX, ele se preocupa não em recriar o texto em um inglês padrão e de leitura confortável para seu público receptor, necessariamente, mas tenta reproduzir determinados efeitos presentes no texto original a fim de manter seu tom e elabora compensações que, sob uma ótica mais tradicional, poderiam ser compreendidas como infidelidades ao texto original. A presença desses elementos, no entanto, tem justamente o objetivo de transmitir aspectos desse texto em italiano em sua versão inglês.

A tradução minorizante, para Venuti, trabalha portanto com o que ele denomina o "remainder", termo que poderia ser traduzido como resto em português, resto no sentido de sobra, especialmente utilizado no âmbito da matemática. Esse resto ou sobra está intimamente ligado à noção de heterogeneidade na tradução proposta pelo autor. Ele ressalta, no entanto, que:

The heterogeneity needn't to be so alienating as to frustrate a popular approach completely; if the remainder is released at significant points in a translation that is generally readable, the reader's participation will be disrupted only momentarily. Moreover, a strategic use of minority elements can remain intelligible to wide range of readers and so increase the possibility of that the translation will cross the boundaries between cultural constituencies. $(1998, \text { p. 12) })^{13}$

Assim, nesse tipo de tradução, a escolha das estratégias a serem utilizadas deve estar em sintonia com o gênero e o estilo do texto original. Além disso, Venuti afirma que a tradução deve levar em consideração também o posicionamento desse texto no sistema literário de origem e sua relação com a literatura do país para o qual está sendo traduzido. No caso de Díaz, essa é uma observação que ganha especial interesse porque se trata de um texto que é vertido para a língua materna do autor, um caso de tradução que não tem como meta uma língua totalmente estrangeira ao texto original. Esse elemento faz com que a necessidade de valorização do posicionamento do texto seja ainda mais relevante.

As reflexões de Venuti sobre tradução apresentam ainda um ponto importante para o presente artigo: a necessidade de um deslocamento em relação à questão da autoria em textos literários traduzidos. Para Venuti (1998), a tradução pode ser lida ela também como uma forma de autoria, no entanto, uma autoria "não originária", derivada, vinculada a um texto anterior.

Tal concepção permite que o trabalho do tradutor supere a sua invisibilidade (outro conceito amplamente trabalhado por Venuti) que é muitas vezes considerada desejável nessa atividade para reposicioná-lo como alguém que "reinvent the text for a specific cultural constituency that differs from the one for which it was initially intended" (1998, p. 44). ${ }^{14}$ Levando em consideração essa ideia do tradutor como um reinventor do texto, torna-se necessário refletir sobre como a obra de Díaz é vertida para o espanhol por seus diferentes tradutores. 


\section{Traduzindo weird English sem perder o sotaque}

Em uma entrevista sobre a tradução de suas obras para o espanhol, Díaz reflete sobre as perdas e ganhos que o texto sofre ao ser vertido para essa língua que de alguma forma também o compõe:

En la versión original hay una confrontación de lucha libre entre el inglés y el español. Hasta cuando se lee la parte en inglés se escucha el español porque las estructuras de las oraciones son bien raras, hay un tono y un ritmo caribeño. Creo que cuando se traduce totalmente al español pierde ese conflicto, esa energía, pero gana una enorme cantidad de intimidad, porque el español es un idioma muy íntimo y brutal, y pienso que la brutalidad interna de la familia salió más fuerte en la versión española. Cuando la mamá de uno le dice "!tú si eres feo!" eso significa algo que "you sure are ugly!" no puede cubrir, no hay manera, el inglés no puede competir cuando se trata de la violencia lingüística parental. (Diaz, en Cespedes 2009, s/n) $)^{15}$

Assim, traduzir, especialmente no caso de textos translinguais como os elaborados por Díaz, mais do que criar um duplo do texto original, tarefa impossível, dever tornar-se um exercício transcultural capaz de gerar um textoirmão, para prosseguir com a metáfora utilizada por Bresner (2007, p. 314). Como então se dá esse processo? Para melhor compreender esse movimento, apresento uma análise das estratégias empregadas nesse sentido na tradução das obras de Díaz, com especial destaque para as versões elaboradas por Achy Obejas.

Cabe, portanto, uma breve apresentação de Obejas. Nascida em Cuba, Achy Obejas é, além de tradutora, autora de obras de ficção como os romances Ruins (2009), Days of Awe (2001), Memory Mambo (1996), livros de poesia tais quais This is what happened in our other life (2007), dos volumes de contos Aguas y otros cuentos, The tower of the Antilles (2017) $e$ We came all the way from Cuba so you could dress like this? (1994) e organizadora de antologias como Immigrant voices: 21st century stories (2014) e Havana Noir (2007). Como tradutora, além de Junot Díaz, é responsável por versões de livros de autores latino-americanos como Wendy Guerra, Carlos Velázquez, Ena Lucía Portela e Rita Indiana. Além disso, atua como docente, coordenando o programa de pós-graduação em tradução (MFA) na Mills College em Oakland, no estado da Califórnia. ${ }^{16}$

Sua escolha para a tradução de The brief and wondrous life of Oscar Wao e de This is how you lose her parte de uma iniciativa do próprio autor. Díaz declarou em mais de uma oportunidade sua insatisfação com as duas traduções para o espanhol realizadas por tradutores ibéricos para Drown, e uma das condições acertadas antes da publicação de seus outros livros foi que ele participasse ativamente da escolha de um novo tradutor. Após um teste às cegas realizado com diferentes nomes, Obejas foi a selecionada.

O resultado é um texto em espanhol bastante diferente das versões publicadas de Drown. Visivelmente preocupada em dar um acento caribenho ao texto. O produto final em ambos os livros traduzidos por Achy Obejas é, na leitura 
que realizo aqui, uma tentativa que pode ser identificada com as perspectivas transcultural e minorizantes já descritas no presente artigo.

Cabe analisar, dessa forma, as estratégias utilizadas pela tradutora para a elaboração de seu texto. Em linhas gerais, acredito que Obejas tenha conseguido dar conta do que propõe D’Amore, pensando uma tradução adequada ao texto de Díaz: "Se puede realizar una traducción en la que se aplica el continuo del espanglish para poder convertir, con matices bilingües, a los enunciados del inglés estadounidense con acento dominicano a un español dominicano apropiadamente anglicado" (p. 36). ${ }^{17}$

Assim, acredito que La maravillosa vida breve de Oscar Wao e Así es como la pierdes são obras que se utilizam do contínuo do spanglish como "ferramenta conceitual" para elaborar em espanhol a hibridez do texto original em inglês, deslocando e compensando elementos bilíngues para o texto em espanhol.

A primeira estratégia, e a mais básica também, a ser destacada nesse sentido, é a não tradução de determinados termos. Em alguns casos em específico, quando as sentenças híbridas podem ser mantidas como no original sem prejuízo para a compreensão do texto, Obejas simplesmente as repete:

Being a loser with capital letter (2012, p. 17)

Se hizo sinónimo de loser con 1 mayúscula (2013, p. 21)

Her english teacher, a deviant, assured that her accent was superb, superb (2007, p. 96)

Su professor de inglês, un depravado, le aseguró que su acento era superb, superb (2008, pp. 102-103)

No, he said with the gravity of an old school pimp (2007, p. 60)

No, dijo él con la gravedad de un chulo old school (2008, p. 66)

Our girl was straight boycrazy (to be called boycrazy in a country like Santo Domingo is a singular distinction (...)) (2008. p.88)

Nuestra chica era straight boycrazy, y que le digan boycrazy a una muchacha en un país como Santo Domingo es una distinción particular. $(2007, \text { p. } 94)^{18}$

A extensa lista de exemplos, longe de esgotar o uso do recurso no romance, tem apenas como objetivo deixar clara a extensão de seu uso no texto de Obejas. Ao manter essas expressões em inglês, ela demonstra a preocupação de transmitir ao leitor um elemento bastante específico do estilo de Díaz: o emprego frequente que sua narrativa apresenta de expressões coloquiais identificadas com uma voz narrativa jovem, especialmente no caso dos textos que seguem o ponto de vista de Yunior.

Uma situação discursiva específica para a qual Obejas tende a manter termos em inglês são os trechos em que se incluem elementos identificados com a cultura nerd ou com a ficção científica em geral: 
Like stumbling into the wizard Shazam's cave of finding the crashed ship of the Green Lantern! (2007, p. 94)

¡Era como tropezar con la cueva del mago Shazam o encontrar la nave estrellada del Green Lantern! (2008, p. 101)

Don't misunderstand: our boy wasn't no ringwraith, but he wasn't no orc either (2007, p. 15)

No se confunda, nuestro muchacho no era ningún ringwraith, pero tampoco era un orc $(2008, \text { p. } 22)^{19}$

Todos os termos mantidos em inglês nesses casos têm traduções para o espanhol Shazam, mencionado no primeiro exemplo, é conhecido como Capitán Marvel e Green Lantern como Linterna Verde no mundo hispânico, e as referências no segundo exemplo são retiradas de Senhor dos Anéis, que também possui algumas traduções para o espanhol, e, portanto, termos para dar conta de ringwraith e orc. A não-tradução desses elementos se dá, dessa forma, com fins estilísticos bastante específicos. Tanto Oscar quanto o narrador Yunior conheceram tais personagens nos Estados Unidos, tiveram acesso aos seus nomes em inglês; mantê-los nessa língua evidencia o caráter dual da formação desses personagens.

Em seu texto mais recente, a crônica "watching Spider-man in Santo Domingo", ${ }^{20}$ publicado na New Yorker, Díaz reafirma o papel fundamental que super-heróis tiveram para a construção da sua ideia do que é a America. Manter esses nomes em inglês contraria grande parte dos manuais de tradução, e, para um leitor purista, essa pode ser vista como uma decisão errada na versão do texto, mas de fato essa escolha reflete a interpretação que Obejas faz do romance com que trabalha.

Obejas também mantém em inglês nomes de espaços importantes para as narrativas, como o condomínio em que vive Yunior e sua família, o London Terrace Apartaments, ao qual ele se refere com frequência apenas como Terrace:

What happens is that in the end, she moves away from the London Terrace (2012, p. 171)

Sucede que a final de cuentas se muda del London Terrace (2013, p. 169)

I'd be back in London Terrace If I wasn't careful and she'd be off to Tokyo or Kyoto or whererver she was going (2007, p. 198)

Sí no tenía cuidado, en um par de meses estariade Nuevo en el London Terrace y ella estaria en Tokio o Kyoto o donde coñazo fuera $(2008 \text {, p. 210 })^{21}$

Na versão em espanhol de Drown, elaborada por Eduardo Lago, o condomínio passa a se chamar Terraza:

If the girl is from Terrace (1996, p. 143)

Si la muchacha es de la Terraza $(1997, \text { p. 123) })^{22}$

Manuais tradicionais de tradução de fato recomendariam a versão do nome, uma vez que, embora se trate de um substantivo próprio, ele possui um 
significado que se perderia com a não-tradução. No entanto, Obejas aposta na semelhança entre as duas palavras para manter o texto na língua original e assim cria um vínculo mais efetivo com o texto original.

Outra estratégia empregada por Obejas, essa por sua vez amplamente explorada no campo dos estudos da tradução, é o estabelecimento de compensações linguísticas. É importante observar, entretanto, que Obejas opera essas compensações em um marco bastante específico, uma vez que em diversas situações não é possível manter o bilinguismo a partir do mero espelhamento entre os textos. Isso fica claro, por exemplo, na tradução de Wildwood feita pelo tradutor colombiano Juan Álvarez, texto inicialmente publicado como conto na New Yorker, mas posteriormente incluído em The Brief Wondrous life of Oscar Wao/La maravillosa vida breve de Oscar Wao. Em sua versão, algumas das frases inteiramente construídas em espanhol atribuídas à personagem Belícia Cabral, mãe de Oscar e Lola, são traduzidas então para o inglês, recurso que mantém a hibridez linguística do texto, mas cria um problema grave de verossimilhança interna: tal personagem não fala inglês, ou o faz com grandes dificuldades (CRESCI, 2014). No trecho abaixo é possível observar o efeito provocado pelo espelhamento:

Que muchacha tan fea, she said in disgust, slashing the rest of her coffee in the sink. Fea's become my new name (2012, p.54)103

What an ugy girl, decía con disgusto, tirando el resto del café en el fregadero. Ugly se convirtió en mi nombre (tradução de Alvarez)

Qué muchacha tan fea, decía disgustada, botando en el fregadero lo que quedaba de su café. Fea pasó a ser mi nuevo nombre (2013, p. 60)

Obejas, portanto, insere no texto em espanhol expressões em inglês que podem ser compreendidas em maior ou menor medida por um leitor nativo de espanhol pouco familiarizado com a língua inglesa. Se Díaz emprega frases inteiras em espanhol em seu texto original, a versão de Obejas, utilizando o contínuo do spanglish, faz o caminho contrário e enxerta elementos em inglês, evidenciando sua compreensão de que a mudança de código no texto de Díaz não é só um recurso linguístico, mas um ato performativo de sua identidade, que pode e deve ser representado em espanhol.

São inúmeros os exemplos desse procedimento nos dois livros traduzidos por Obejas, dos quais seleciono alguns para melhor ilustrar a questão:

Me and Magda were on an upswing (2012, p.3)

Magda y yo habíamos recuperado nuestro flow (2013, p. 15)

You can start the laugh track anytime you want (2007, p.171)

Pueden echar a andar el soundtrack de risas cuando le de la gana (2008, p. 181$)^{23}$

No primeiro trecho, retirado da narrativa inicial de This is how you lose her Así es como la pierdes, Yunior faz referência ao relacionamento com Magda, a 
namorada por ele traída que ressoa em vários dos textos que compõem o livro. Fica claro a partir da justaposição dos dois trechos que, para dar conta da expressão coloquial "on an upswing" e, ao mesmo tempo manter algo do bilinguismo do texto, Obejas insere a palavra "flow", de compreensão mais simples para falantes de espanhol do que "upswing".

Já no segundo, retirado de The Brief Wondrous of Oscar Wao \La Maravillosa Vida Breve de Oscar Wao, Obejas opta por utilizar uma palavra semelhante à empregada no texto original, "soundtrack", no lugar "laugh track". Esse cuidado permite que o texto mantenha seu efeito bilíngue, sem, no entanto, se tornar opaco para o leitor. Trata-se de um caso clássico de compensação, uma vez que reproduz um efeito presente no texto original, mas não necessariamente no mesmo local em que esse efeito se apresenta.

Essas compensações também parecem cumprir o papel de manter o ritmo do texto original. Como observa Ch'ien (2004) em seu livro Weird English, a inserção de palavras em espanhol nos trechos em inglês na obra de Díaz faz com que o texto ganhe outro ritmo de leitura, uma vez que as palavras em espanhol trazem consigo o acento característico da língua. As traduções de Obejas, ao fazer o caminho contrário, levam ao espanhol algo do timo do inglês quando incluem palavras como "flow".

Outro recurso recorrente na tradução feita por Obejas é o emprego de neologismos identificados com a fala da comunidade hispânica dos Estados Unidos originalmente ausentes no texto de Díaz:

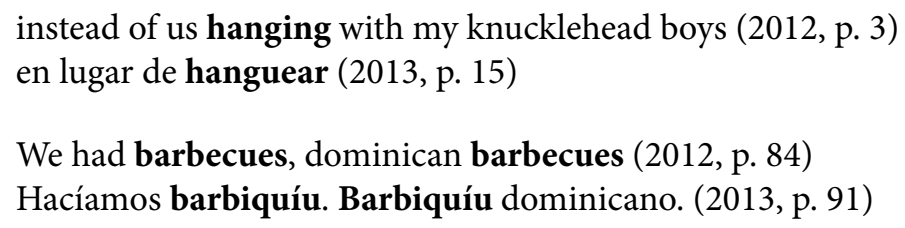

Anyway, after a few weeks on overdrive (2012, p. 94)

Enigüey, después de andar unas semanas así a mil (2013, p. 100)

I started getting really scared (2012, p. 114)

Empecé a frikiar (2013, p. 118)

Start attending to meetings (2012, p.176)

Comiezas a ir a mítines (2013, p. 174)

You take a break (2012, p. 186)

Tomas tu breiquecito (2013, p. 183)

Baseball (2007, p. 109)

Béisbol (2008, p. 117) ${ }^{24}$

Embora partam todos da mesma lógica - a adaptação de palavras em inglês para o sistema fonético da língua espanhola -, os processos de formação dessa numerosa lista de exemplos são bastante diversos. Alguns, como béisbol, são mais amplamente usados em espanhol em diversos países, já outros, como hanguear, 
bróder, mítine, barbiquiu e breiquecito, representam expressões identificadas com o spanglish e comumente associadas à fala jovem.

Empregar termos como esses não só estabelece o efeito translinguístico também no texto de Obejas como o faz de forma extremamente coerente com a voz narrativa de Yunior. Não se observa o uso desse recurso em nenhum dos contos ou capítulos, no caso do romance, que não são contados a partir do ponto de vista de Yunior.

Sobre esse procedimento em específico, merece destaque o que talvez seja um dos termos mais frequentes na obra de Díaz e que, segundo a própria tradutora, foi um dos que mais ofereceu dificuldades para ser vertido ao espanhol ${ }^{25}$ : o onipresente palavrão "fucking". Os tradutores espanhóis de Drown optaram na maior parte dos casos pelo apagamento da expressão, Obejas, diante da dificuldade de se encontrar uma expressão pejorativa com o mesmo peso e que ocupasse uma posição similar na sentença, optou pelo emprego de "fokin", uma versão hispanizada do termo

em inglês, frequentemente utilizada por indivíduos da comunidade Latina nos Estados Unidos.

Nos exemplos abaixo é possível observar alguns dos trechos em que Obejas substitui fucking por seu correlato hispanizado fokin:

You are a guest in here, he said. You should be earning your fucking keep" (2012, p. 33)

Tú éres la visita aquí, debes contribuir con el fokin mantenimiento de la casa $(2013$, p. 43)

And what about that supersonic culo that could tearwords right out of niggers' mouths, pull Windows from out their motherfucking frames? (2007, p. 56)

Y que hay del culo supersónico que les sacaba a borbotones las palabras a los tipejos del barrio y arrancaba las ventanas de sus fokin marcos? (2008, p. 61$)^{26}$

Como contraponto, seguem trechos comparativos retirados de Drown e de sua versão em espanhol realizada por Eduardo Lago, Negocios:

She looks out the window, all tagged over with initials and fuck you's (1996, p. 49)

Se asoma a la ventana, alrededor del marco está todo pintado de iniciales y malas palabras (1997, p. 43)

Fuck me, I say. (1996, p. 93)

Seré pendejo, digo. (1997, p. 81)

What a fucking asshole (1996, p.146)

Menudo pendejo comemierda (1997, p. 126) ${ }^{27}$

Torna-se claro, a partir da comparação entre as duas versões, que Lago opta por construir sentenças bastante mais conservadoras, apresentando um 
equivalente em espanhol e organizando a frase de acordo com a ordem canônica da língua. O resultado é um texto domesticado, para utilizar o termo empregado por Venuti (1998) para se referir a traduções que têm por objetivo oferecer ao leitor uma leitura o menos estrangeira possível, mas que tradicionalmente são consideradas exemplos de fidelidade.

Ainda comparando as diferentes traduções de Díaz, também merece destaque as diferentes abordagens de trechos que podem ser considerados sexualmente explícitos, bastante frequentes em todos os livros do autor.

Shower, comb, dress. Sit on the couch and watch TV. If she's an outsider her father will be bringing her, maybe her mother. Neither of them want her seeing any boys from the Terrace - people get stabbed in the Terracebut she's Strong-headed and this time will get her way. If she's a whitegirl you'll at least get a handjob (1996, p. 144)

Dúchate, péinate, vístete. Siéntate en el sofá y ponte a ver la televisión. Si la muchacha es de fuera la traerá su padre en carro, tal vez su madre. Ni a uno ni a otra les gustan nada los muchachos de la Terraza — en la Terraza apuñalan a la gente - pero ella es testaruda y por esta vez se saldrá con la suya $(1997, \text { p. } 124)^{28}$

No exemplo em questão, evidencia-se a estratégia utilizada para dar conta de "at least get a handjob": a supressão da frase inteira. É importante observar, no entanto, que a eliminação de expressões que não oferecem uma equivalência clara em espanhol é um procedimento de uso constante também nas versões de Obejas, isso pode ser observado, por exemplo, com a expressão "knucklehead boys" no primeiro conto de This is how you lose her $\backslash$ Asi es como la pierdes (2012, p. 3), suprimida na versão em espanhol. Em diversos momentos, apagamentos desse tipo são realizados. Para manter um texto verossímil, é necessário sacrificar elementos que poderiam comprometer o caráter informal do texto se traduzidos. Não é esse o caso no exemplo retirado de How to date a browngirl, blackgirl, whitegirl, o halfie. No trecho da tradução de Lago, a sentença parece ser eliminada por conta de seu explícito caráter sexual, como ocorre em outros trechos de Negocios.

Ainda descrevendo os processos de compensação empregados pela tradutora, Obejas também insere termos hispânicos que Díaz usa com alguma frequência, mesmo em contextos em que o texto original não o faz:

but it's our kids you see in the streets and hanging from the porches."(2012, p. 42)

pero son nuestros carajitos los que se ven hangueando por la calle y por las terrazas (2013, p. 51)

Dude was supposed to have atomic level G, was supposed to be pulling in the bitches with both hands (2007, p. 24)

se suponía que fuera un tíguere salvaje con las hembras, se suponía que las estuviera atrapando a dos manos. (2008, p. 26)

What the hell am I wasting my Money for (2007, p. 134)

Para qué coñazo estoy gastando mi dinero $(2008, \text { p. } 140)^{29}$ 
Sobre esse tipo de compensação, na já citada entrevista de Obejas a José Eduardo González, a tradutora afirma que desenvolveu ao longo do trabalho com The brief wondrous life of Oscar Wao o que ela chama de um "diccionario de Junot-speak", uma vez estabelecidos determinados parâmetros a partir do texto de Díaz, ela passou a empregá-los recorrentemente. Esse procedimento fez com que a tradução de This is how you lose her fosse bastante mais rápida do que a de The brief wondrous life of Oscar Wao, ao mesmo tempo em que possibilitou uma notável unidade entre os dois livros traduzidos por Obejas.

Outro dos procedimentos de compensação empregado por Obejas é o uso de elementos identificados com um registro extremamente coloquial do espanhol caribenho para, de alguma forma, manter o tom do inglês do gueto no qual se expressam os narradores de Díaz.

Um recurso que merece destaque nesse sentido é o emprego de palavras grafadas de forma a reproduzir esse registro em espanhol, como exemplo "cuidao", "demasiao" e "jodío", ainda que essas palavras apareçam no texto original com a ortografia tradicional:

Dude used to say he was cursed (2007, p. 171)

El tipo siempre decía que estaba asarao $(2008$, p.181)

No one, and I mean no one, was into them the way Óscar was (2007, p. 173)

Nadie, y quiero decir nadie, estaba tan metío con ellas como Óscar (2008, p. 183$)^{30}$

O fenômeno do apagamento do /d/ intervocálico em formas de particípio é extensamente estudado pela linguística descritiva do espanhol, e um fenômeno amplamente difundido não só na República Dominicana, mas no Caribe hispânico em geral e em algumas regiões da Espanha. Embora se trate de um traço coloquialmente utilizado por diversos grupos sociais, trata-se de um traço ainda bastante estigmatizado, especialmente quando reproduzido na escrita (ALBA, 2003). O uso desse recurso por Obejas, como deixam claro os exemplos acima, contribui para que o texto em espanhol recupere a fluência e a informalidade que caracterizam o discurso de Yunior.

Com frequência, Obejas também inclui reduções identificadas com o espanhol de Santo Domingo; é o caso de "pa na" em sua substituição a "para nada". O objetivo do uso desse recurso parece o mesmo do apresentado no parágrafo anterior: dar ao texto um tom informal verossímil de acordo com a comunidade a que se vincula culturalmente.

That one's too lazy to do anything, his wife said with no little exasperation (2007, p. 96)

Ese vago no sirve pa' ná, contestaba su esposa un tanto exasperada (2008, p. 103$)^{31}$ 
Pa na, no entanto, é uma expressão bastante transparente e facilmente identificável pelo contexto da obra. Em diferentes trechos Obejas também inclui elementos identificados com o dialeto dominicano que podem representar obstáculos para um leitor familiarizado com outras variantes do espanhol:

Life was not always pleasent. Plenty of acts of violence, plenty of beatdowns and knifings (2007, p. 122)

Pero la vida no siempre era agradable. Un montón de actos de violencia, un montón de piñas y puñalazos (2008, p. 130)

Gangster was a man of the world, had fucked more prietas (2007, p. 129) Gángster era un hombre del mundo, había singao con más prietas de las que podía contar (2008, p. 134)

Santo Domingo was to Pópola what Switzerland was to Chocolate (2007, p. 150)

Santo Domingo era pala popola lo que Suiza es para chocolate (2008, p. $156)^{32}$

Ao optar por incluir léxico próprio da comunidade dominicana em detrimento de escolhas que poderia ser entendida como mais neutras, Obejas assume uma posição estética, mas também política. Ao elaborar um texto que soa caribenho, ela ativamente trabalha para a consolidação dessas obras no sistema interliterário que a abriga. Esse recurso, assim como o bilinguismo de Díaz no texto original, não deve ser enxergado como mera tentativa de imprimir cor local, mas compreendido como uma opção lúcida e absolutamente consciente do papel que as variantes dialetais desempenham na formação de identidades culturais.

Outro fenômeno mantido por Obejas do texto de Díaz, ou inserido em trechos em que o autor originalmente não o faz, típico do espanhol caribenho, é o chamado lambdacismo, também descrito por Orlando Alba (2003):

Santo Domingo was to popóla what Switzerland was to chocolate (2007, p. 150)

Santo Domingo era pala popola lo que Suiza era para el chocolate (2008, p. 156)

What did you know about Nueba Yol or unheated "old law" tenements or children whose self-hate short circuited their minds? (2007, p. 178)

¿Qué sabías de Nueba Yol o de viviendas sin calefacción de la "vieja ley" o de niños con tanto odio a sí mismos que les provocaba cortocircuito en la cabeza? $(2008 \text {, p. } 185)^{33}$

O lambdacismo é um dos traços fonéticos mais característicos do dialeto caribenho, e consequentemente do dialeto caribenho-americano. Tanto seu emprego por Díaz quanto sua ampliação no texto de Achy Obejas fortalecem a ideia de identificação cultural a partir do reconhecimento de elementos linguísticos.

Embora seja uma escritora cubana, fica claro a partir desse conjunto de estratégias que Obejas tentou aproximar o texto o máximo possível do dialeto da 
terra natal do autor. Essa estratégia cumpre um papel duplo: ao mesmo tempo em que aproxima a narrativa da realidade dominicana, a torna mais estrangeira para leitores de outras nacionalidades. Sobre essa questão, Obejas afirma que empreendeu um intenso trabalho de pesquisa sobre o espanhol dominicano. Ao longo dos quase dez meses que levou para traduzir o romance, a tradutora declara ter lido dicionários de gírias, ouvido muitas horas de programas de rádio locais e lido muitos textos literários publicados na República Dominicana.

Trata-se, portanto, de um texto que leva em consideração seu público leitor e se esforça para, abandonando qualquer ilusão de neutralidade, entregar uma versão que abraça a diferença e tenta contribuir para a formação de identidades culturais, como sugere Venuti (1998) sobre a tradução minorizante.

Uma estratégia também utilizada por Obejas é o emprego de recursos gráficos não utilizados por Díaz para recuperar determinados sentidos no texto, como ilustra o seguinte exemplo, anteriormente trabalhado na reflexão sobre a relação com a língua inglesa mantida por imigrantes latinos de primeira geração nos EUA:

a week later he was seeing some other girl. She was from Trinidad, a cooca pañyol, and she had this phony-as-hell English Accent. It was the way we all were back then. None of us wanted to be niggers. Not for nothing. (2012, p. 39)

a la semana ya tenía outra novia. Una Cocoa-Panyol de Trinidad, con um acento inglés falso. Así es como éramos todos entonces. Nadie quería ser negro. Pa-ra na-da. (2013, p. 48$)^{34}$

A divisão em sílabas da expressão " $\mathrm{Pa}$-ra na-da" no fim do parágrafo não repete um recurso utilizado no texto em inglês. No entanto, ela imprime ao texto a intensidade que a frase curta no fim do parágrafo, tão característica da obra de Díaz, possui. Ao mesmo tempo, a separação silábica pode ser compreendida como uma tentativa de recuperar o ritmo próprio da oralidade, dando ênfase ao enunciado. Trata-se, portanto, de uma compensação estilística da tradutora, fato que demonstra que os procedimentos de compensação não se limitam às questões linguísticas.

A tradução não se resume, no entanto, aos procedimentos de compensação linguística supracitados. Em diversos momentos, Obejas também realiza uma das operações descritas por D’Amore como parte das práticas identificadas com a tradução minorizante, como a reelaboração de referências culturais:

The higher echelons (2007, p. 117)

Los mayimbes (2008, p.123)

Leticia, just off the boat (2007, p. 26)

Leticia, acabadita de bajar de la yola (2008, p. 28) ${ }^{35}$

Como no caso do emprego de léxico do espanhol dominicano, aqui o que se observa é a opção por elementos que tenham referência direta com a cultura 
desse país. "Mayimbe", a palavra utilizada no segundo exemplo como equivalente para "Echelon", é um termo indígena, um remanescente taíno, que designa um líder ou chefe. Ainda que de uso recorrente no espanhol caribenho, a opção por uma palavra de uso local, desconhecida para a maior parte dos falantes nativos de espanhol, é muito significativa.

Um caso parecido ocorre no segundo exemplo, quando a tradutora adapta uma expressão tradicional americana que se refere pejorativamente ao imigrante recém-chegado, substituindo "boat" por "yola" uma palavra dominicana utilizada para um tipo pequeno de embarcação historicamente utilizada para viagens ilegais para Porto Rico.

Para melhor visualizar o resultado obtido pelo emprego desse conjunto de estratégias de compensação, é interessante observar sua interação em uma amostra textual mais extensa. No trecho abaixo, um dos mais tensos de The brief and Wondrous life of Oscar Wao/La maravillosa vida breve de Óscar Wao, se descreve o episódio de violência sexual que marca a personagem Lola, irmã do protagonista do romance:

Now that her crazy years were over - what dominican girl doesn't have those?- she'd turned one of those tough Jersey dominicanas, a long distance runner who drove her own car, had her own checkbook, called men bitches, and would eat a fat cat in front of you without a speck of vergüenza. When she was in fourth grade she'd been attacked by an older acquaintance, and this was common knowledge throughout the Family (Paterson, Union City y Teaneck), and surviving the urikán of pain, judgment, and bochinche had made her tougher than adamantine (2008, pp. 24-25)

Ahora que había concluido su temporada de locura - ¿Qué muchacha dominicana no pasa por una?- se había convertido en una de esas dominicanas duras de Jersey, corredora de largas distancias, con su propio carro, su proprio talonario de cheques, que les decía perros a los hombres, y se comía lo que le daba la gana sin una gota de vergüenza, especialmente si el tipo tenía baro. Cuando estaba en el cuarto grado la había asaltado un hombre mayor al que le conocía del barrio; esto fue vox populi en toda la familia, (Y por extensión una buena parte de Paterson, Union City y Teaneck) y el hecho de que pudiera sobrevivirse urikán de dolor, enjuiciamiento y bochinche, la había hecho más fuerte que la adamantina $(2008 \text {, p. 26) })^{36}$

No parágrafo em que se descreve Lola, vários dos recursos descritos anteriormente podem ser observados conjuntamente. A expressão "fat cat", utilizada em seu contexto original para designar uma pessoa poderosa, abastada, é substituída por tipo que tem "baro", uma gíria dominicana da época em que se passa o romance para se referir ao dinheiro. Já “common knowledge”, expressão identificada com um registro mais formal da língua, se torna “vox populi”, citação em latim que acompanha essa mudança de registro. Ainda nessa mesma frase, aparece o neologismo "urikán", uma adaptação fonética de "hurricane", que se mantém na tradução, obedecendo à tendência de Obejas a manter as palavras 
criadas por Díaz. Por último, esse trecho se encerra com uma referência nerd, adamantina, uma alusão ao metal indestrutível que compõe o esqueleto de Wolverine, um dos mutantes de X-Men. A análise desse parágrafo deixa clara a complexidade da leitura que o texto demanda e o minucioso trabalho de tradução empreendido por Obejas.

Outro elemento bastante marcante na prosa de Díaz e já observado por autores como Evelyn Nien-Ming Ch'ien (2004) é a presença abundante de um tipo bastante rico de metáfora, que incorpora frequentemente elementos identificados com a cultura nerd, mas também imagens de diferentes origens. Nas traduções, Obejas frequentemente precisa encontrar alternativas para essas construções, e esse é um dos principais pontos de divergência entre suas versões e os trabalhos realizados anteriormente com Drown $\backslash$ Los boys $\backslash$ Negocios. Nos exemplos abaixo, é possível observar as versões de algumas metáforas retiradas de The brief and Wondrous life of Oscar Wao/La maravillosa vida breve de Óscar Wao e This is how you lose her/Así es como la pierdes:

His life started going down the tubes (2007, p. 16)

Su vida empezó a irse al carajo (2008, p. 17)

And when Lola puts an end to something, she puts an end to it hard (2007, p.169)

Y cuando Lola pone fin a algo, es un frenazo (2008, p.178)

Getting in or out some roughneck's ride (2007, p. 18)

Subiendo y bajando del carro de algún matón (2008, p. 19)

Me, who had pussy coming out of my ears? (2007, p.165)

Yo, que tenía chocha hasta en la sopa? $(2008, \text { p. 197) })^{37}$

Obejas também oferece, de distintas formas, especialmente em sua tradução para The brief and wondrous life of Oscar Wao, explicações para as referências nerds tão marcantes no texto de Díaz. A inserção de notas ausentes no texto original é uma das estratégias nesse sentido, mas a inclusão de explicações ausentes no texto original também:

Eso lo llevaría al otro vigilante, el superser del universo Marvel que está al lado azul de la luna y mira y mira, pero jamás interviene (2008, p. 22)

That would lead him to another watcher, the one who lamps the dark side of the moon $(2007, \text { p. } 20)^{38}$

Obejas em determinados momentos também altera sentenças originalmente em espanhol:

Call out to passing women - Tú eres guapa! Tú eres guapa! (2007, p. 13) Les gritaba a las mujeres que pasaban - !Tu ta buena, Tu ta buena! (2008, p. 13$)^{39}$ 
No trecho da primeira parte de Oscar Wao, o protagonista ainda criança fala com mulheres na rua. A alteração em questão parece ter como objetivo tornar o discurso infantil mais próximo do espanhol coloquial dominicano e, portanto, mais verossímil. No contexto caribenho, o termo "guapa(o)" é coloquialmente um sinônimo para brava(o) ou valente e não possui o sentido de beleza comum em outras regiões falantes de espanhol e empregado por Díaz. Esse exemplo deixa claro que em várias ocasiões é necessário traduzir não apenas o inglês, mas também as construções que já se encontram em espanhol.

As estratégias de manutenção do tom do texto original não se manifestam, no entanto, apenas no léxico. Cabe observar que o texto de Díaz mantém no inglês elementos da sintaxe do espanhol. Nas versões de Obejas, em muitos casos se pode observar o movimento contrário como forma de compensação, o emprego da sintaxe influenciada pelo inglês em frases em espanhol:

What do you think, these were free? (2007, p. 96)

¿Qué tu crees, que estas cosas son de gratis? (2008, p. 104)

Where are you going, morena? $(2007$, p. 123)

¿Y adonde tú vas morena? (2008, p. 127)

you watching this shit again? (2007, p.172)

¿Tú ta mirando esa mierda otra vez? $(2008, \text { p. } 181)^{40}$

A principal estratégia nesse sentido parece espelhar um elemento bastante comum na prosa de Díaz: o apagamento de pronomes em posição sujeito. Obejas, em várias situações, marca esse tipo pronome contrariamente à tendência elíptica do espanhol, como se pode observar nos três exemplos, todos eles com a presença de " $t u$ ' em contextos em que esse termo poderia ser facilmente subentendido.

A tradução de Obejas também se mostra preocupada com a manutenção dos vários neologismos empregados por Díaz:

Two Truji-líos in a lifetime - what carajo else could be? (2007, p. 155)

¿Dos Trujilíos en el curso de su vida? ¿Qué carajo podia ser si no eso? (2008, p. 160)

A consumate culocrat to the end $(2007$, p. 167)

Um culócrata consumado hasta el final (2008, p. 172) $)^{41}$

Em outro exemplo desse mesmo fenômeno, Obejas reproduz o processo morfológico empregado por Díaz para gerar um termo equivalente:

Despite the trove of men, handsome, plain, and ugly, who marched into the restaurant intent on winning her hand in marriage (or at least in fuckage) (2007, p. 107)

A pesar del fracatán de hombres, hermosos, sencillos y feos, que entraban en el restaurante con el propósito de ganar su mano en matrimonio (o por lo menos en fokinmonio) $(2008, \text { p. } 111)^{42}$ 
Em um último exemplo desse recurso, Obejas recria em espanhol um arcaísmo utilizado por Oscar. Nesse caso não se trata de uma palavra inventada por Díaz, mas o termo "copacético", não dicionarizado em espanhol, portanto uma criação de Obejas, representa com fidelidade a escolha lexical de Díaz:

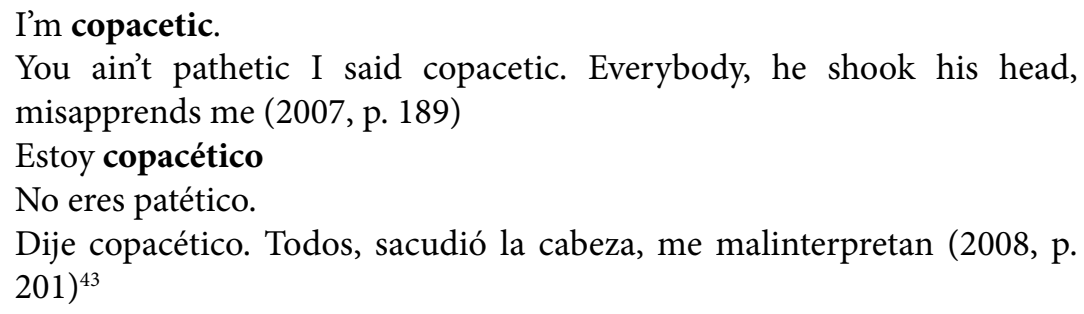

Nos quatro exemplos observados, fica claro que Obejas se preocupou em criar equivalentes coerentes para os termos criados por Díaz. A opção pela não substituição dessas palavras por outras dicionarizadas revela uma preocupação típica da tradução minorizante, preocupada com a manutenção do caráter estrangeiro do texto.

Cabe observar também que os deslocamentos de voz narrativa efetuados por Díaz têm implicações diretas na construção textual, os quais são acompanhados na tradução. Em textos narrados por personagens diferentes de Yunior, como Otravida, Otravez, de This is how you lose her $\backslash$ Así es como la pierdes, narrado por Yasmín, uma imigrante dominicana que se relaciona com um conterrâneo casado que deixou a família no país de origem, isso é facilmente observável. Nessa narrativa, o ponto de vista explorado é o da amante, da outra, e ela o faz através de um discurso quase que integralmente em inglês padrão. Não há no texto a presença das gírias identificadas com o gueto ou as referências à cultura pop norte-americana, tão frequentes nos textos narrados por Yunior; a narradora, nesse caso, deixa claro que sua única linguagem é o espanhol.

A tradução de Obejas para textos como esse segue esse padrão e tem como resultado uma versão monolíngue em espanhol que, em sintonia com o seu trabalho como tradutora de Díaz no geral, consegue em grande medida reproduzir o tom do texto original. Assim, nesses casos em que as vozes narrativas são personagens que só se comunicariam em espanhol, o texto traduzido se torna uma versão ainda mais verossímil do que o original em inglês. O exemplo abaixo fornece elementos que corroboram essa leitura:

Here is what the wife looks like. She is small with enormous hips and the grave seriousness of a woman who will be called doña before she's forty. I suspect if we were in the same life we would not be friends. (2012, p. 67)

Su mujer es así: pequeña, con enormes caderas y la grave seriedad que le toca a una mujer a quién llamarán doña antes que cumpla los cuarenta. Sospecho que si viviéramos la misma vida jamás seríamos amigas. $(2013, \text { p. } 75)^{44}$

Nesse parágrafo a narradora descreve a esposa deixada na República Dominicana. Há no texto original um elemento em espanhol, mas de fato se trata 
de uma forma de tratamento carregada de um peso cultural que dificilmente seria transmitido por algum termo semelhante em inglês. No texto em espanhol, como se pode observar, não é realizado nenhum procedimento de compensação da frase bilíngue. O parágrafo em espanhol, no entanto, não apresenta perdas consideráveis de sentido com esse apagamento.

Tal exemplo é especialmente interessante para evidenciar que os procedimentos de compensação utilizados por Obejas para tentar dar conta das estruturas bilíngues de Díaz não têm como único objetivo a manutenção de um discurso em duas línguas, mas sim uma certa fidelidade ao tom do texto, que em determinados casos prescinde do emprego de termos em inglês. Nesse caso em específico, o emprego de quaisquer termos em inglês relacionados a uma personagem que teve a experiência da migração já na vida adulta, que provavelmente não tem um nível médio-formal de escolarização e que mesmo nos Estados Unidos se relaciona quase que exclusivamente com outros latinos, soaria pouco verossímil e inadequado em relação ao texto original.

Ainda que extensa, a lista dos procedimentos levados a cabo por Achy Obejas para a tradução dos livros de Díaz aqui elaborada não esgota o primoroso trabalho empreendido pela tradutora. Seja a partir da contraposição entre seu texto e o original, seja através da comparação com a tradução de Drown, fica clara a existência de um projeto, tanto estético quanto político, de valorização do espanhol caribenho e do translinguismo que caracteriza a prosa diaspórica de Díaz.

\section{Considerações finais}

Com o presente artigo buscou-se demonstrar que a tradução, por tanto tempo associada com o ato de traição, pode se opor ferrenhamente a essa concepção tornando-se, antes, um recurso fundamental para impulsionar a circulação do objeto literário. Para assumir esse papel, no entanto, a tradução precisa desvencilhar-se das falsas concepções sobre fidelidade, outro conceito bastante cristalizado no imaginário dessa atividade, rejeitando, portanto qualquer tentação de domesticação do texto original.

Torna-se evidente, portanto, que no caso da elaboração de traduções de textos já originalmente concebidos hibridamente essa preocupação com a não domesticação deve ser ainda mais intensa. Nesses casos, fornecer ao leitor uma experiência mais próxima da leitura do original não passa necessariamente pela opção por estratégias de tradução mais tradicionalmente vistas como fiéis, mas passa pela criação de alternativas para a manutenção da riqueza das narrativas diaspóricas.

Fica claro também que o ato de traduzir rejeitando essas concepções tradicionais é um exercício altamente complexo e que merece atenção da crítica, uma vez que pode ser compreendido como uma forma de autoria derivada, para citar o termo empregado por Venuti. Dar essa centralidade ao tradutor na crítica é um movimento de reconhecimento desse profissional que pode efetivamente contribuir para a reversão do que esse mesmo autor chama de invisibilidade da tradução. 
Os livros de Díaz, especialmente nas versões traduzidas por Achy Obejas, são claros exemplos desse movimento que torna autor e tradutor um binômio que precisa ser compreendido conjuntamente. É fundamental que a tradução receba a atenção especializada que merece, especialmente quando veículo para a inserção do autor em um sistema literário que também o engloba, como é o caso de escritores diaspóricos, que inegavelmente se deslocam nesse espaço transliterário contemporâneo.

O estudo atencioso do trabalho de Obejas com os textos de Díaz revelou uma gama de recursos existentes para a manutenção do tom bilíngue do texto original na versão traduzida. Seja a partir de compensações, de substituições, da criação de neologismos ou do emprego de recursos fonéticos próprios da oralidade caribenha. Obejas de fato construiu um texto irmão para os livros de Díaz, reposicionando-os dentro de um espaço a que também pertencem.

Assim, mais do que meramente transpor a obra para a língua espanhola, Obejas empreendeu um processo transcultural tão afinado ao texto original que repete um de seus aspectos mais ricos, sua riqueza política. Ao negar-se a elaborar um texto homogeneamente escrito em um espanhol tido como neutro, Obejas reconhece a produtividade literária de formas linguísticas frequentemente estigmatizadas e subalternizadas.

Esse movimento é também revelador em si de uma concepção bastante particular da linguagem não só como mero recurso de comunicação, mas sim como atividade marcadamente política, mesmo que em um contexto de elaboração estética como é o caso do texto literário. Reconhecer e valorizar a língua do migrante, sem exotizá-la ou apresentá-la como inferior é dar a ela um espaço necessário e que precisa ser ampliado.

Em um mundo marcado por trânsitos de pessoas e informações cada vez mais rápidos e volumosos, torna-se fundamental ver na tradução um poderoso movimento transcultural, capaz de efetuar mediações, reduzir diferenças e aproximar realidades conflitivas. Encarar a tradução também como objeto artístico, portanto, é mais do que um movimento desejável, um imperativo para a compreensão adequada do mundo contemporâneo.

No discurso de entrega do prêmio Pulitzer afirmou-se que Díaz é um escritor americano, lidando com o cotidiano da América. Não é nenhum exagero afirmar, portanto, que ele faz do espanhol uma língua americana ao incorporá-la em suas obras. Obejas faz o caminho contrário, tão necessário e rico quanto, ao devolver essa obra também latino-americana às suas origens. Há uma complementaridade tão inegável quanto bela nesses dois movimentos.

\section{Notes}

1. O presente artigo é parte da pesquisa de doutorado que resultou na tese intitulada Extraterritorialidade e translinguismo na obra de Junot Díaz, orientada pela Prfa. Dra. Elena Palmero González.

2. "Através do estranhamento da linguagem, escritores pós-coloniais podem se colocar face a face com a realidade da differance, e questionar a supremacia da 
linguagem padrão." Todas as traduções de textos cíticos e teóricos no presente artigo foram elaboradas por mim; as citações de textos literários acompanham as traduções das edições brasileiras indicadas nas referências bibliográficas.

3. uma das coisas sobre a escrita em inglês é que existem certos membros da minha audiência que eu claramente queria que pudessem ler esses textos, mas que não leem em inglês, então eu pensei que eles acabariam por ser traduzidos informalmente por um dos membros da minha família. Isso é o mais longe que eu cheguei a pensar originalmente sobre tradução (DÍAZ, 2002, p. 43).

4. A tradução desempenhou um papel significativo na criação de estereótipos do Outro, como produtos derivados da domesticação e da imposição cultural.

5. Tradução e transculturação, embora sejam termos analiticamente diferenciáveis, são, no entanto, processos que na prática se superpõem. $O$ ato da tradução caprichosamente adiciona camadas de significado, assim como o processo de transculturação: A não simplesmente se dissolve e desaparece em $\mathrm{B}$, mas sim ambos interagem de forma complexa e imprevisível produzindo algo novo, digo um A1 e um c C, para citar as variáveis lindamente conjugadas por Alejandro Saravia em uma passagem de seu romance citada por José Antonio Giménez Micó.

6. O turbulento e imprevisível processo resultante da interação entre culturas em contato que proporciona, apesar das desiguais relações de poder, a emergência de novas formas culturais (2007, p. xi)

7. Autores também proporcionam frequentemente introduções e posfácios, escrevem ensaios críticos comentando seus próprios textos, ou facilitam comentários "autorizados" sobres seu trabalho. De fato, nós chegamos a compreender melhor porque autores pós-coloniais abraçam tais tipos textuais e estratégias literárias se consideramos as funções de elementos similares para tradutores.

8. O termo original é "foreignizing" optamos nesse trecho por sua tradução literal, foraneizante, porque é a forma empregada por D’Amore. Venuti, no entanto, também trabalha com a ideia de "minoritizing translation", traduzido nesse artigo como tradução minorizante.

9. As traduções fluidas requerem o investimento de um menor esforço devido a sua lealdade primaria para com a língua e cultura destino, e não ao texto original (TO) e sua língua e cultura. Em contraste, a dificuldade relativa de uma tradução foraneizante serve como um recordatório da alteridade do TO, através de intervenções que ressaltam o fato de que o texto traduzido (TT) é efetivamente um texto traduzido, de um texto produzido em Outra língua, em Outras circunstâncias, em Outro contexto.

10. Afrontar estes atos de etnocentrismo, uma prática que não contribui para a criação de estereótipos nem para a supressão cultural, mas sim que tenha como meta respeitar a alteridade do TO.

11. Como uma força coletiva, uma montagem de formas que constituem um regime semiótico.

12. Nunca levantar um novo padrão ou estabelecer um novo cânone, mas sim promover inovação cultural assim como o entendimento da diferença cultural através da proliferação de variáveis dentro do inglês.

13. A heterogeneidade não precisa ser tão alienante a ponto de frustrar o apelo popular completamente; se o resto é depositado em pontos significativos e a tradução é no geral compreensível, a participação do leitor será interrompida apenas momentaneamente. Além disso, um uso estratégico de elementos minoritários pode se manter inteligível para uma grande parcela dos leitores e assim aumentar 
a possibilidade de que a tradução atravesse fronteiras entre grupos culturais distintos.

14. Reinventar o texto para uma constituição cultural específica que difere daquela para a qual ele foi inicialmente projetado.

15. Na versão original há uma confrontação de luta livre entre o inglês e o espanhol. Mesmo quando se lê a parte em inglês é possível escutar o espanhol. Porque as estruturas das orações são bem pouco usuais, há um tom e um ritmo caribenho. Creio que quando se traduz totalmente para o espanhol esse conflito se perde, essa energia, mas se ganha uma enorme quantidade de intimidade, porque o espanhol é um idioma muito íntimo e brutal, e acho que a brutalidade interna da família ficou mais forte na versão espanhola. Quando a mãe de alguém diz "! tú si eres feo!" isso significa algo que "you sure are ugly!” não pode cobrir, não há como, o inglês não pode competir quando se trata da violência linguística parental. (Díaz, en Cespedes 2009, s/n)

16. Informações disponíveis no website de Achy Obejas: https://achyobejas.com/ about/ Acesso em: 02 de outubro de 2017.

17. Pode-se realizar uma tradução na qual se aplica o contínuo do espanglish para poder converter, com matizes bilíngues, aos enunciados do inglês estadounidense com sotaque dominicano a um espanhol dominicano apropriadamente anglicizado (p. 36).

18. Virou sinônimo de perdedor com P maiúsculo (2013, p. 24)\Seu professor de inglês, um tarado, assegurou que tinha uma pronúncia notável, notável (2009, p. 70)\ Não, disse ele, com a gravidade de um cafetão calejado (2009, p. 61) \louca por meninos (uma distinção bastante peculiar numa região como Santo Domingo (...) $(2009, \mathrm{p} .65)$.

19. Como descobrir por acidente Um anel, achar a pedra da eternidade do mago Shazam ou encontrar a espaçonave caída do lanterna verde! (2009, p. 69) Não me entenda mal: nosso garoto não era um cavaleiro negro, nem um orc. (2009, p. 83).

20. Disponível em: https:/www.newyorker.com/magazine/2017/11/20/watchingspider-man-in-santo-domingo. Acesso em: 21 de novembro de 2017.

21. No fim das contas, a Srta. Lora se muda do London Terrace. (2013, p. 104) \Se eu não agisse logo, em alguns meses voltaria para London Terrace, e ela iria para Tóquio ou Kioto ou seja lá onde estivesse indo (2009, p.139).

22. Se a garota é do Terrace (1998, p.127).

23. A Magda e eu estávamos numa fase pra lá de boa. (2013, p. 15)\Podem começar a rir, se quiserem (2009, p. 178).

24. Em vez de a gente ficar (2013, p. 10)\A gente fazia churrascos. Churrascos dominicanos. (2013, p. 55)\Seja como for (2013, p. 70)\ quase surtei. (2013, p. $72) \backslash$ começa a frequentar as reuniões (2013, p. 108)\Você dá mesmo um tempo (2013, p. 163)\Até mesmo no decorrer desse período conturbado Beli tinha seus pretendentes, sujeitos (2009, p. 76)\Beisebol (2008, p.78).

25. Obejas afirma isso na entrevista concedida a José Eduardo González. Disponível em: https://www.viceversa-mag.

26. Você é que é a convidada aqui, comentou Rafa. Devia contribuir para a porra do seu sustento. (2013, p. 40)\Sem falar naquele traseiro supersônico que arrancava elogios constantes das bocas dos caras e deixava todo mundo boquiaberto (2009, p.78).

27. Ela aparece na janela, toda coberta de iniciais e palavrões (1998, p. 120)\Fodeu, eu digo (1998, p. 90) \Que idiota fodido (1998 p. 120). 
28. Tome banho, penteie o cabelo, troque de roupa. Sente no sofá e comece a ver televisão. Se a garota é de fora seu pai vai trazê-la de carro, talvez sua mãe. Nem um nem outro gostam nada dos garotos do Terrace-no Terrace apunhalam gente - mas ela é teimosa e vai dar um jeito. Se for branca você consegue pelo menos uma punhetinha. (1998, p. 89).

29. mas são os nossos filhos que se veem nas ruas (2013, p.31)\o cara tinha que dominar o jogo no nível atômico, ter legiões de mulheres gostosas loucas por ele (p. 43)/ Por que é que estou gastando a porra do meu dinheiro? (2009, p. 136).

30. O cara costumava dizer que era amaldiçoado (2009, p. 120)/ninguém mesmo, gostava de minas como o Oscar (2009, p. 123).

31. Aquele lá é um preguiçoso, não move uma palha, respondeu a esposa, muito exasperada. (2009, p. 103).

32. Sua vida nem sempre era um mar de rosas. Inúmeros atos violentos, incontáveis espancamentos e esfaqueamentos foram perpetrados.(2009, p. 68)\Gângster era um cara mundano, que tinha trepado com tanta prieta que já tinha perdido a conta e não ligava para essa zorra (2009, p. 70)\Santo Domingo estava para a popóla como a Suíça está para o chocolate. (2009, p. 103).

33. Até hoje têm vários sujeitos em Baní, antigos clientes, que se lembram muito bem da garçonete (2009, p. 48)/sua vida nem sempre era um mar de rosas. Inúmeros atos violentos, incontáveis espancamentos e esfaqueamentos foram perpetrados. (2009, p. 68)\Gângster era um cara mundano, que tinha trepado com tanta prieta que já tinha perdido a conta e não ligava para essa zorra (2009, p. 70)।Santo Domingo estava para a popóla como a Suíça está para o chocolate. (2009, p. 103).

34. Uma mulher de Trinidad, uma cocoapañyol, com um sotaque americano falso pra cacete. Era assim que a gente se sentia naquela época. Nenhum de nós queria fazer parte da comunidade negra. Não a troco de nada. (2013, p.38).

35. turma do alto escalão (2009, p. 82) \Leticia, ingênua e inexperiente (2009, p. 32).

36. A irmã de Oscar, Lola, era bem mais realista. Agora que seus anos de rebeldia haviam terminado - que moça da $\mathrm{RD}$ não passa por eles? -, ela virara uma daquelas dominicanas de Nova Jersey, uma maratonista com carro e talão de cheque próprios que chamava os homens de putos e traçava ricaços na frente da gente sem a menor vergüenza. Quando estava na quarta série foi atacada por um conhecido mais velho, fato que era do conhecimento geral da família (e, por extensão, de boa parte de Paterson, Union City e Teaneck), e sobreviver a esse urikán de dor, crítica e bochinche deixou Lola mais resistente que adamantino. (2008, p. 23).

37. Sua vida começou a desandar (2009, p. 19)\E quando ela dava um basta a algo, não voltava atrás nem a pau (2009, p. 156)/Entrando e saindo do carro de algum babaca (2009, p. 21)/Eu? Que tinha mulher saindo pelo ladrão? (2009, p.200).

38. o levaria até outro observador, um Vigia que assistia a tudo na Área Azul da Lua (2009, p.33).

39. mexia com as transeuntes: Tú eres guapa! Tú eres guapa! (2009, p. 12).

40. Está pensando o quê? Que tudo isso é de graça? (2009, p. 64) \E aonde você vai, morena?(2009, p. 81)\Está vendo esta porra de novo? (2009, p. 121).

41. Dois Truji-líos, em uma só vida - que outro carajo poderia ser? $(2009$, p.104)〉 Culocrata inveterado até o fim $(2009$, . 116).

42. Apesar das levas e mais levas de caras charmosos, comuns e feios que entravam no restaurante determinados a pedir sua mão em casamento (ou ao menos em transamento) (2009, p. 77). 
43. Eu me sinto lépido. Você não é patético. Eu disse lépido. Todo mundo, afirmou, meneando a cabeça, interpreta mal o que digo (2009, p. 133).

44. Sua mulher é assim: pequena, com enormes quadris e a grave seriedade que toca a uma mulher a quem chamarão de dona antes que faça quarenta anos. Suspeito que se vivêssemos a mesma vida não seríamos amigas. (2013, p.75).

\section{Referências}

ALBA, O. Cómo hablamos los dominicanos: un enfoque sociolinguistico. BYU Scholars Archive, 2003. Disponível em: <http://scholarsarchiv.byu.edu/books/3>. Consulta em 23 de maio de 2017.

BESNER, N. Translating North and South: Elizabeth Bishop, Biography and Brazil. in CHEADLE, N.; PELETIER, L. Canadian Cultural Exchange: Translation and Transculturation/Échanges culturels au Canada. Traduction et transculturation. Waterloo: Wilfrid Laurier UP, 2007.

BASSNETT, S.; TRIVEDI, H. (Orgs). The postcolonial translation. London: Routledge, 2002.

CESPEDES, D. Que es la traduccion para Junot Diaz? Em Hoy Digital 07/03/2009. s/n. Disponível em: <http://www.hoy.com.do/areito/2009/3/7/269254 /Quees-latraduccion-para-Junot-Diaz>. Consulta em 10 de maio de 2016.

CHEADLE, N.; PELETIER, L. Canadian cultural exchange: Translation and Transculturation / Échanges culturels au Canada. Traduction et transculturation. Waterloo: Wilfrid Laurier UP, 2007.

CH'IEN, E. N. Weird English. Massachussets: Harvard press, 2004.

CRESCI, L. K. Simultaneidad linguistica la ficción de Junot Díaz y su traducción. RECIAL/Revista del CIFFyH Área Letras, n. 5-6, dic. 2014. Disponível em: $<$ https://revistas.unc.edu.ar>. Consulta em 02 de abril de 2017.

D’AMORE, A. M. Traducción en la zona de contacto. Mutatis Mutandis. Vol. 3, No. 1. 2010. pp. $30-44,2010$.

DERRIDA, J. In SILVA, F. de F. da. As voltas com Babel: Derrida e a tradução (catacrestica). 2006, 205 p. Tese (doutorado) - Universidade Estadual de Campinas, Instituto de Estudos da Linguagem, Campinas, SP. Disponível em: $<$ http://libdigi. unicamp.br/document/?code=vtls000381759>. Acesso em: 28 mar. 2017.

DÍAZ, J. Drown. New York: Riverhead, 1996.

DÍAZ, J. Los boys. Barcelona: Mondadori, 1996.

DÍAZ, J. Negocios. Trad. Eduardo Lago. New York: Vintage español, 1997.

DÍAZ, J. Afogado. Rio de janeiro record, 1998.

DÍAZ, J. The brief and wondrous life of Oscar Wao. New York: Riverhead Books, 2007.

DÍAZ, J. La maravillosa vida breve de Óscar Wao. Trad. Achy Obejas. Barcelona: Mondadori, 2008.

DÍAZ, J. A fantástica vida breve de Oscar Wao. Trad. Flávia Carneiro. Rio de Janeiro: Record, 2009.

DÍAZ, J. This is How you lose her. New York: Riverhead, 2012.

DÍAZ, J. Así es como la pierdes. Trad. Achy Obejas. Barcelona: Mondadori, 2013.

DÍAZ, J. É assim que você a perde. Rio de Janeiro: Record, 2013.

DÍAZ, J. (Org.) The beacon best of 2001: Great writing by Women and Men of all colors and cultures. Beacon press: Boston, 2001. 
RUSHDIE, S. Imaginary homelands. London: Granta books, 1991.

TIMOCZKO, M. Post-colonial writing and literary transltion. in BASSNETT, S.; TRIVEDI, H. (Orgs). The postcolonial translation. London: Routledge, 2002.

VENUTI, L. The scandals of translation: Towards an ethics of difference. Routledge, Nova Iorque: 1998.

VENUTI, L. The translator's invisibility: a History of translation. Nova Iorque: Routledge, 2008.

Recebido: $16 / 11 / 2018$

Aceito: 04/02/2019 